\title{
Aspirations as reference points: an experimental investigation of risk behavior over time
}

\author{
Arvid O. I. Hoffmann · Sam F. Henry • \\ Nikos Kalogeras
}

Published online: 13 July 2012

C The Author(s) 2012. This article is published with open access at Springerlink.com

\begin{abstract}
This paper examines the importance of aspirations as reference points in a multi-period decision-making context. After stating their personal aspiration level, 172 individuals made six sequential decisions among risky prospects as part of a choice experiment. The results show that individuals make different risky-choices in a multi-period compared to a single-period setting. In particular, individuals' aspiration level is their main reference point during the early stages of decision-making, while their starting status (wealth level at the start of the experiment) becomes the central reference point during the later stages of their multi-period decision-making.
\end{abstract}

Keywords Aspirations - Multi-period decision-making - Reference points · Risk-behavior · Risky-choice

\footnotetext{
A. O. I. Hoffmann $(\bowtie) \cdot$ S. F. Henry

Department of Finance, School of Business and Economics, Maastricht University,

P.O. Box 616, 6200 MD Maastricht, The Netherlands

e-mail: a.hoffmann@maastrichtuniversity.nl
}

\section{A. O. I. Hoffmann}

Network for Studies on Pensions, Aging and Retirement (Netspar),

P.O. Box 90153, 5000 LE Tilburg, The Netherlands

\section{N. Kalogeras}

Department of Marketing and Supply Chain Management, School of Business and Economics, Maastricht University, P.O. Box 616, 6200 MD Maastricht, The Netherlands

\section{N. Kalogeras}

European Center of Corporate Engagement (ECCE), School of Business and Economics, Maastricht University, P.O. Box 616, 6200 MD Maastricht, The Netherlands 


\section{Introduction}

Risky-choice behavior is often reference-dependent (Sugden 2003; Bleichrodt 2007). Prior work shows that typical reference points are individuals' own current wealth or endowment (Kahneman and Tversky 1979; Munro and Sugden 2003). Recent research, however, suggests that aspiration levels may also serve as reference points (Payne et al. 1980; Endres 2006; Page et al 2007; Diecidue and Van De Ven 2008). Therefore, current models of risky-choice start to include multiple reference points, which is especially relevant in real-life choice contexts with repeated decision-making (Sullivan and Kida 1995; Liu and Colman 2009).

A key feature of such multi-period decision-making is that individuals may initially base their decisions on aspiration levels that may or may not coincide with later reference points. A pioneering model that addresses the role of aspiration levels is SP/A theory (Lopes 1987). Subsequent studies on reference-dependency show that reference points can change over time (Lim 1995; Heyman et al. 2005; Munro and Sugden 2003; Schmidt 2003; Bleichrodt 2007; Arkes et al. 2008). Outcome framing and the results of preceding decisions, for example, influence a choice's perceived riskiness (Weber and Milliman 1997; Cohen et al. 2008) and the basis for evaluating choices changes as new choice situations occur (Gooding et al. 1996).

Recent extensions on shifting and multiple reference points (including aspirations) make reference-dependency models more complete and dynamic. Decision-making under risk over the longer term, however, remains under-examined. This is surprising, as aspirations are generally defined as goals that cannot be realized in an instant, but require multiple decisions over time. Dellavigna and LiCalzi (2001) state that there is a lack of experimental research that examines the evolution of risk-behavior over time. To better understand how individuals in markets behave when facing repeated decision-making under risk, there is a need for studies on multi-period decisions (see e.g., Payne et al. 1980; Ackert et al. 2006).

The current paper contributes to filling this void in the literature and examines the importance of aspirations as reference points through an experimental elicitation of decision-maker preferences within a multi-period context. The paper is organized as follows. Section 2 reviews the literature. Section 3 presents the conceptual framework. Section 4 describes the methodology and experimental design. Section 5 presents the results. Section 6 concludes.

\section{Literature review}

\subsection{Reference-dependence theories}

Since prospect theory (Kahneman and Tversky 1979) challenged the principles of expected utility theory, reference-dependence theories gained ground. According to prospect theory, decision-makers evaluate choices in terms of changes in wealth from a reference point, creating a "loss domain" below and a "gain domain" above the reference point. Decision-makers are generally risk-averse in the gain and risk-seeking in the loss domain. Another distinguishing feature of prospect theory is that the utility function is steeper in the loss than in the gain domain. Moreover, it is concave in the 
gain and convex in the loss domain. A final key aspect of prospect theory is its nonlinear transformation of the probability scale: Individuals overweight small probabilities and underweight moderate and high probabilities.

The concept of a reference point is flexible. Heath et al. (1999) claim that goals serve as reference points and show they can inherit the properties of prospect theory's value function. Aspiration levels are also included as reference points in studies on risky-choice (Diecidue and Van De Ven 2008). A prominent example of such a model is SP/A theory (Lopes 1987). According to this theory, individuals assess risky-choices not only in terms of their security and potential aspects, but also for their attractiveness relative to an aspiration level.

\subsection{Shifting and multiple reference points}

Evidence on prospect theory suggests that decision-makers adjust their reference point in response to changes in wealth (Munro and Sugden 2003; Arkes et al. 2008). Bleichrodt (2007) supports shifting reference points by claiming that real-life choice behavior is better explained by allowing such shifts. Schmidt (2003) argues in favor of shifting reference points by stating that preferences between alternatives may change if the status-quo is varied.

The idea of shifting reference points becomes more complicated with multiple reference points. Kahneman and Tversky (1979) state that several factors, such as an individual's status-quo or aspiration level, may influence the reference point. It remains unclear, however, whether both the status-quo and aspiration level can simultaneously function as reference points. Building on this premise, this paper examines how riskychoice behavior evolves over time in a context with multiple reference points. As such, we respond to Gooding et al. (1996), who conclude that two assumptions of prospect theory, namely reference-point stability and the number of reference points, have escaped empirical examination to date.

\subsection{Multi-period decision-making}

Aspirations represent outcomes of human decision-making processes. These outcomes can be part of the indirect opportunity set, as individuals often have to make multiple decisions to reach their aspirations. Previous work, however, mainly examines singlechoice decisions where reference points are part of the direct opportunity set (Sullivan and Kida 1995; Heath et al. 1999). Overall, these studies suggest that individuals choose the alternative that provides them with the highest probability of reaching their most important reference point, irrespective of whether they "like" the risk of that alternative (Shefrin and Statman 2000).

Surprisingly, however, empirical research on multi-period decision-making is scarce (Loewenstein 1988; Rachlin 1990; Loewenstein and Prelec 1991). Most existing work is theoretical, such as Dellavigna and LiCalzi (2001). In these authors' model, individuals show a dual-risk attitude in the short run (i.e., individuals are risk-averse over gains while they are risk-seeking over losses), but learn to make risk-neutral choices over the longer run. 
In multi-period decision-making, it is important to consider how prior outcomes influence individuals' choices during the course of decision-making. Current decisions can be evaluated based on both the current choice options and the history of these choice options. Tversky and Kahneman (1981) state that decision-makers either use a minimal account and include only the direct consequences of an act or use an inclusive account where prior outcomes affect choices. With respect to the latter, Thaler and Johnson (1990) show that individuals take more risk after realizing a gain. Prior losses, however, make individuals more risk-averse unless the current choice offers the potential to eliminate the prior loss.

Another challenge is to examine how reference points are updated as a function of prior outcomes. Whenever one outcome follows another, the consequences of the second outcome depend on the adaptation of an individual's reference point to the first outcome (Arkes et al. 2008). The relative position of the reference point is one determinant hereof. The importance attached to each reference point is likely adjusted according to experienced gains or losses.

\section{A framework for analyzing aspirations and risk-behavior over time}

This paper proposes and tests a conceptual framework in which individuals make decisions under risk based on their reference point(s), prior outcomes, and a time constraint (Fig. 1). The starting status (defined as the status-quo at $t=0$ ), the statusquo at each step of the multi-period decision-making process, and the initially stated aspiration level may all function as a reference point. The extent to which each of these reference points is considered depends on the decision-maker. In the experiment presented in this paper, decision-makers set a fixed aspiration level before starting their multi-period decision-making. The time constraint is based on the number of "framework cycles," which in this paper is six consecutive decisions.

\subsection{Hypothesis 1: single-period versus multi-period risk- behavior}

A typical assumption in decision-making research is that individuals wish to maximize their ex-post result, which would generate the highest utility. It is also plausible, however, that decision-makers wish to minimize the chance of a low ex-post result instead, thereby preventing a major loss in utility. The latter means, for example, that

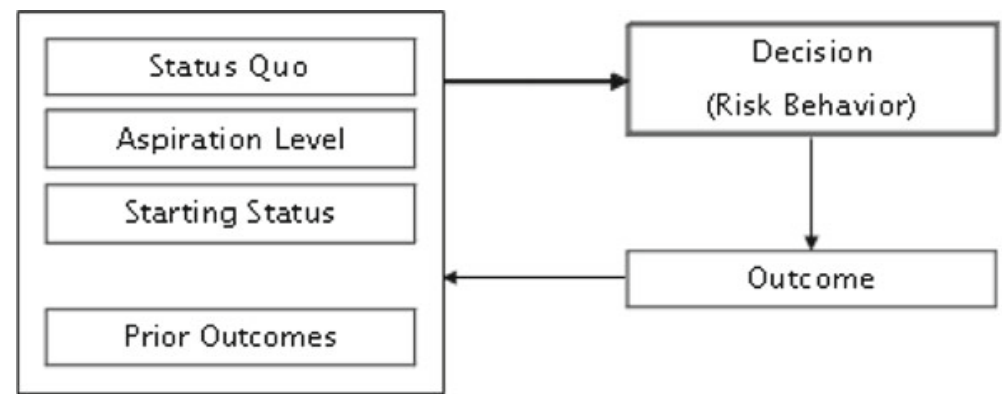

Fig. 1 Conceptual framework 
because of loss aversion, most individuals will choose not to play a gamble with a $50-50 \%$ chance of losing or winning 500 Euros. In this example, the individual's status-quo functions as a reference point. Yet, in the presence of an aspiration (e.g., someone aspires to win at least something), the gamble might be preferred (recall aspirations as a second choice criterion in SP/A theory). In both cases, individuals make a single decision. What would happen if the same individuals have to consecutively choose whether or not to gamble several times? Will preferences change? The following example stresses the importance of making such multiple decisions.

Scenario 1 Imagine you are going to the casino at $21.00 \mathrm{~h}$ and that you will stay until closing time, $22.00 \mathrm{~h}$. In the casino, you can either play games of poker or spend your time on small horse-racing tournaments. Both a poker game and a horse-racing tournament last one hour each. Based on the buy-in and the skills of the other players, the prospect of a poker game looks as follows: (0.8, -125; 0.2, 500). Playing one horse-racing tournament has the following prospect: $(0.5,-50 ; 0.5,50)$. You equally like poker and horse racing. You would be happy if you could take an extra 100 Euros back home, but this is not of utmost importance.

Scenario 2 Imagine Scenario 1, but now you are going to the casino at $18.00 \mathrm{~h}$.

In the first scenario, you have to make a single decision, namely to play one poker game, to play one horse-racing game, or not to play at all. This choice depends on how you assess the risks attached to each game, how much (dis)utility you assign to each outcome, and the extent to which your aspiration (take home an extra 100 Euros) influences you. In the second scenario, you face the same decision. Now, however, you have the opportunity to sequentially make this decision several times. Will your choice at $18.00 \mathrm{~h}$ in Scenario 2 be the same as the one at $21.00 \mathrm{~h}$ in Scenario 1? After all, in Scenario 2 you will have the possibility to later "correct" the choice you took at $18.00 \mathrm{~h}$, whatever the outcome of this choice turns out to be. It is here also important to consider the extent to which the aspiration influences an individual. For example, if you chose to play a poker game first, and lost, your subsequent decisions might aim to quickly recover your loss (and even reach your aspiration) by playing another poker game, which has the riskier prospect. Instead, though, you might choose to play some horse-racing games to try and recover your loss, thereby taking a more cautious approach. As yet another option, you might come to peace with your loss and stop playing. In addition, the probability of reaching a certain reference point changes over time, as the variance in outcomes shifts. Knowing this might influence decisionmakers in terms of their risk-behavior, even when the status-quo and the prospects faced remain the same. All in all, individuals likely act differently when making a single decision versus multiple decisions.

$\mathbf{H}_{1}$ In the presence of an aspiration, individuals' single-period risk- behavior differs from their multi-period risk-behavior.

\subsection{Hypothesis 2: relative importance of reference points}

The extent to which aspirations influence decision-makers' choices depends on their relative importance compared to other possible reference points. In the aforementioned 




Fig. 2 The value function with multiple reference points

scenarios, the starting status is the amount of money taken to the casino. The statusquo after losing a poker game is this amount minus 125 Euros. The aspiration in this scenario is the initial amount of money plus 100 Euros. In prospect theory, the starting status often serves as a reference point and receives special attention, since falling below this point is perceived as a loss, while exceeding it as a gain. A decision-maker, however, may consider the aspiration of winning an extra 100 Euros similarly, namely that not reaching this aspiration constitutes a loss, while reaching or exceeding it a gain. Hence, the relative importance of both reference points determines the degree of risktaking. Recall that decision-makers generally become risk-seeking when positioned below a reference point and risk-averse when positioned above it. In the presence of two reference points, the value function of prospect theory can thus be depicted as in Fig. 2. When the starting status and aspiration level receive equal attention, decisionmakers are expected to show a mixture of risk-seeking and risk-averse behavior when they are positioned between both reference points (see e.g., Sullivan and Kida 1995).

Revisiting the prior scenarios, an aspiration of taking home an extra 100 Euros could be reached in the single-period decision context (Scenario 1). It can also be reached in the multi-period decision context (Scenario 2). An aspiration of taking home more than an extra 500 Euros, however, can only be reached in Scenario 2. The starting status as a reference point can be reached in any scenario by not playing at all. Individuals who worry more about going home with less money than they came with than about reaching their aspirations are expected to act in a risk-averse manner because of loss aversion and the starting status acting as the main reference point. In contrast, individuals for whom only the aspiration matters are expected to become risk-seeking, because they are positioned in the loss domain of the value function. Finally, individuals focusing on both the starting status and the aspiration are expected to exhibit a mixture of risk-seeking and risk-averse behavior, depending on their position. In a multi-period decision context, the latter case is especially interesting.

Let's first focus on aspirations as reference points in a multi-period setting. Recall that an aspiration is usually part of an individual's indirect opportunity set, something which can only be reached by making multiple decisions over a longer time period. During this repeated decision-making, individuals will now and then reflect on their status-quo to check whether their aspiration is still reachable with the current strategy 
or whether more or less risk needs to be taken in subsequent decisions. This evaluation is important, as it makes individuals recalculate their chances, which can change their risk-behavior. For example, individuals become more risk-averse the more they evaluate past outcomes (Gneezy and Potters 1997). In this discussion, time constraints are critical: If individuals notice they have a low chance of reaching their aspiration given that only a few decisions are left, they might not take big chances and still try to reach it, but act carefully and lower their aspiration to a realistic level.

Now consider the situation where many decisions can still be made (i.e., in the early stages of a multi-period decision-making context). In this situation, decision-makers may feel relatively optimistic because several opportunities to reach their aspiration still exist. This reasoning is strengthened by the anticipation effect (Loewenstein 1987), according to which the delayed "consumption" of a desire (i.e., reaching the aspiration) creates additional utility. Also, during the early stages, little reflection has taken place that could have attenuated this optimism (see Benartzi and Thaler 1995; Gneezy and Potters 1997; Zeisberger et al. 2012).

By including the starting status as the second reference point in the previous discussion, the time constraint becomes even more important. Recall the situation where several decisions can still be made. As previously indicated, the aspiration will likely receive considerable attention at this point. At the same time, the starting status will receive attention because in the early stages the distance to this point is still relatively small. Furthermore, the starting status is considered as a result of individuals' aversion to losses. Loss aversion might be weakened during the early stages, however, as there is still time for corrective actions during later stages. Also, the anticipated additional utility that reaching the aspiration gives dominates the disutility that losses create. Diecidue and Van De Ven (2008) argue that continuity of the utility function is not satisfied at the aspiration level. Rather, outcomes resulting in reaching or exceeding the aspiration level receive more weight.

In the other situation, where the time constraint is approaching and only a few decisions can still be made, the starting status will receive more attention. This may happen because of the evaluation of remaining opportunities and the increased emphasis on the aversion to losses: There is no time left for corrective actions. For most decisionmakers, this "all or nothing" situation is dominated by a concern about ending up with nothing. This argumentation is supported by the status-quo bias, according to which decision-makers disproportionately stick to the status-quo instead of opting for a risky alternative because of loss aversion (Samuelson and Zeckhauser 1988). Thus, during the later stages of multi-period decision-making, the starting status is expected to act as (an additional) main reference point.

$\mathbf{H}_{2}$ In the context of multi-period decision-making under risk, the aspiration level will act as main reference point during the early stages of decision-making, while the starting status becomes an important reference point during the later stages.

\subsection{Hypothesis 3: influence of prior outcomes}

Several studies show the influence of prior outcomes on individuals' risk-behavior. Thaler and Johnson (1990) and Sullivan and Kida (1995), for example, indicate that 
individuals are generally more willing to take risks after a realized gain (the "housemoney effect") and less willing to take risks after a realized loss. Weber and Zuchel (2005) provide similar findings. In general, individual decision-makers' strategies are subject to change when outcomes are realized. Yet, it remains unclear how prior outcomes influence risky decision-making in a multi-period decision-making context with aspiration levels. Here, we develop hypotheses on how prior outcomes impact subsequent risk-taking behavior given such contextual features.

With respect to experiencing one prior gain in the early stages of a multi-period decision-making setting, individuals are expected to subsequently take less risky actions, because the aspiration level is closer and enough decisions are left to be made: The potential to reach the aspiration is strong and the necessity of taking risks decreases. Indeed, Denrell (2004) claims that risk-taking is a decreasing function of the performance-aspiration gap.

In the case of having experienced one prior loss, the findings of Thaler and Johnson (1990) suggest that decision-makers would become more risk-averse, unless the prior loss can be eliminated (the "get-evenitis effect"). The get-evenitis effect is important to consider in a multi-period setting, because the possibility to get even increases when more time and decision opportunities are available. Therefore, especially during the early stages, a prior loss is expected to induce more risk-averse behavior, because it is not necessary to immediately recoup the loss. More risk-averse behavior can also be expected because of myopic loss aversion (Benartzi and Thaler 1995), according to which decision-makers' concern with short-term losses prevents them from taking the risks necessary to reach long-term goals. When decision-makers experience two consecutive prior losses, they will become more risk-averse, primarily for the reasons outlined for the case of one prior loss. Other factors driving a change to risk-averse behavior are the performance-aspiration gap and evaluation of past outcomes (Gneezy and Potters 1997). In case of two prior losses, individuals may stop focusing on their (too ambitious) aspiration and adapt to risk-averse behavior because of a newly set, but lower, target in combination with reflecting upon more prior evaluations.

Regarding two consecutive prior gains, we expect that the aforementioned housemoney effect will play an important role. Decision-makers are likely to take riskier actions, because the potential to reach the aspiration is perceived to be strong, so that the possibility of a little downfall in wealth might become acceptable (the two prior gains cushion a subsequent loss).

$\mathbf{H}_{3}$ In the context of multi-period decision-making under risk with aspiration levels, prior gains and losses influence subsequent behavior as follows: $(\mathrm{a} / \mathrm{b})$ one prior gain or loss induces more risk-averse behavior, (c) two prior gains induce more risk-seeking behavior, and (d) two prior losses induce more risk-averse behavior.

\section{Materials and methods}

\subsection{Subjects, instructions, and procedure}

In exchange for partial course credit, 217 Dutch undergraduate students participated in an experiment. The experiment was conducted in a university lab containing identical 
cubicles, each supplied with a PC. After reading the instructions and answering several questions, subjects were briefed that the remainder of the experiment would be performed using the PC. Subjects were presented with the same instructions and used the same experimental program.

\subsubsection{Set of instructions}

Page one of the instructions described the experiment and informed subjects that they could win a monetary reward. Page two instructed subjects to imagine the following situation:

You have planned to go to the casino for ' 3 hours' in order to (try to) win money. The amount of money you take with you is 100 Euros. You are a big fan of slot machines, but there are 3 different kinds. After every ' 30 minutes' you decide between either switching to another slot machine or staying at the one you are playing. So, in total you will make 6 subsequent decisions. After every '30 minutes,' you will know what you won or lost. Find below the descriptions of the possible outcomes and their probabilities at the 3 slot machines. You do not have to make any decisions yet.

- Slot Machine A: $(45 \%, 40 ; 10 \%, 0 ; 45 \%,-40)$

- Slot Machine B: $(50 \%, 30 ; 10 \%, 0 ; 40 \%,-30)$

- Slot Machine C: $(60 \%, 15 ; 10 \%, 0 ; 30 \%,-15)$

- Fourth option: Every "30 minutes" of not playing gives 3 Euros from your parents.

The prospects of the slot machines were explained, and it was explicitly stated that slot machine $\mathrm{A}$ is the riskiest one, machine $\mathrm{B}$ a bit less risky, and machine $\mathrm{C}$ the least risky. Page three contained questions to test subjects' comprehension of the information on the second page and stressed that the outcomes of their decisions on the computer were not controlled by the researchers, but random. Page four measured several descriptive background variables.

\subsubsection{Computer program}

After subjects finished reading the set of instructions, a computer program was run in full screen on their PCs. This part of the experiment was programmed and conducted with the experimental software $z$-Tree (Fischbacher 2007). The program was divided into two parts: In Part I, subjects had to make their decisions, in Part II, a short questionnaire was presented.

Part I. First, subjects had to state their aspiration level, that is, the total amount of money they would like to have at the end (after the "3 h"). Letting subjects state their own aspiration level increases their involvement and makes it more likely that they convey their true disposition towards their aspiration in the decision context at hand. After stating their aspiration level, the reward description appeared on the screen, explaining subjects' chance of winning the monetary reward (see Sect. 4.4, Incentive scheme). It was checked whether each subject read the reward description 


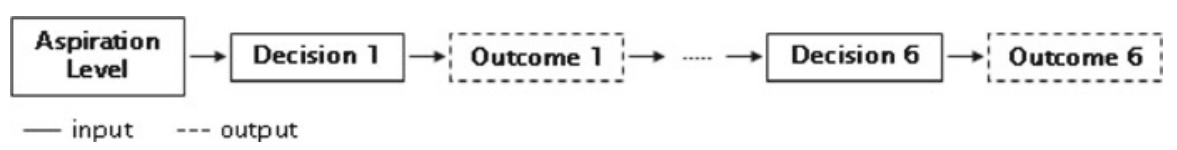

Fig. 3 Input/output structure of the experiment

by identifying the amount of time subjects stayed on this screen. Next, subjects had to make their first decision. The outcome of this decision was shown on the next screen, together with their starting status (i.e., 100 Euros), updated status-quo, and stated aspiration level. Figure 3 depicts the input/output structure of the program.

Part II. After subjects finished making their decisions, a questionnaire was started that probed their satisfaction, happiness, and regret for their decisions with respect to the final result (total amount of money after "3 h"). Their age and gender were also collected.

\subsection{Manipulation}

To investigate the differences in risk-behavior among different situations, it was necessary to randomize the outcomes of subjects' decisions such that each situation of interest received an adequate sample size. An often-chosen option here is to manipulate the outcomes a priori by setting, for example, a gain path versus a loss path (see e.g., Heyman et al. 2005). To ensure the integrity of the university's research lab and avoid subject deception, however, in this study all paths were determined by a random-number generator. That is, researchers did not control the outcomes of subjects' decisions. Each subject had his/her own unique path.

\subsection{Incentive scheme}

To extract true risk preferences, individuals must be confronted with a goal-based incentive scheme (Itami 1976). Without incentives, individuals might become uninvolved, act carelessly, and not make decisions congruent with their real predisposition towards risk. In this paper's experiment, the incentive scheme is set-up to elicit neither overall conservatism nor carelessness, but subjects' natural preferences and behavior. Subjects were informed that five of their names would be randomly drawn after the experiment was completed, and those individuals would receive in cash the money they had won with their decision-making.

\subsection{Data screening}

Prior to the analyses, the experimental data were screened for consistency and correctness. First, we checked whether the computer program generated the right output. No errors occurred because the outcomes after subjects chose slot machine A were 40,0 , or -40 , and nothing else. The same screening was done for slot machines B and $\mathrm{C}$, and the parent option. Second, we checked whether subjects' perceived riskiness 
of the slot machines was in line with the experiment's instructions, namely, that slot machine $\mathrm{A}$ is the riskiest machine, $\mathrm{C}$ the least risky, and $\mathrm{B}$ in between. Thirty-two subjects $(15 \%)$ responded in an inconsistent manner and were excluded from further analysis. Third, we checked whether subjects' aspiration level was above the starting status, which would be in line with the assumption that decision-makers generally want to perform above their current level. Thirteen subjects for which this was not the case were excluded. In the end, 172 subjects remained for further investigation.

\subsection{Pre-test and manipulation check}

We conducted a pre-test to check whether individuals perceived the prospect of slot machine A as riskier than that of slot machine B, and the prospect of slot machine B as riskier than that of slot machine $\mathrm{C}$. If so, choosing slot machine $\mathrm{A}$ can be taken as risk-seeking behavior and choosing slot machine $\mathrm{B}$ or $\mathrm{C}$ as risk-averse behavior. The pre-test also intended to determine an appropriate starting status to increase subjects' involvement in the experiment.

Thirty students, who did not participate in the main experiment, had to indicate on a scale from 1 to 10 how risky they perceived the following prospects:
A: $(45 \%, 50 ; 10 \%, 0 ; 45 \%,-50)$
B: $(50 \%, 50 ; 10 \%, 0 ; 40 \%,-50)$
C: $(60 \%, 50 ; 10 \%, 0 ; 30 \%,-50)$

Note that the percentages are similar to those of the prospects of slot machines A, B, and $\mathrm{C}$, respectively, while the absolute values are constant. In addition, 41 students had to indicate, on a scale from 1 to 5 , to what extent they agreed with the following statements:

The chance of winning or losing $\mathbf{3 0}$ Euros is riskier than the chance of winning or losing 50 Euros.

The chance of winning or losing $\mathbf{3 0}$ Euros is riskier than the chance of winning or losing 15 Euros.

Note that the absolute values are different, while the chances remain the same. The results of the three prospects indicate that the higher the chance of winning, the lower the perceived riskiness (ANOVA results: $M(\mathrm{~A})=5.70 ; M(\mathrm{~B})=4.63 ; M(\mathrm{C})=3.77, p$ values, .03 and. 09, respectively). The results of the two statements suggest that the chance of winning or losing a higher amount is seen as riskier than the same chance of winning or losing a smaller amount (test-value $=3 ; p<.001$ and $p=.113$, respectively). Taking these results together, choosing slot machine A represents the most risk-seeking behavior, choosing slot machine $\mathrm{B}$ medium risk-seeking behavior, and choosing slot machine $\mathrm{C}$ the least risk-seeking behavior. Individuals also were asked how much money they would take to a casino when the intention is to win money. Because 50 and 100 Euros were the first two modes and the mean was 71, 100 Euros was considered an appropriate starting status for this study's experiment. 


\section{Results}

\subsection{Single versus multi-period risk-behavior}

To test for differences between multi- and single-period risk- behavior $\left(\mathrm{H}_{1}\right)$, we compare subjects' decisions made at $t=5$ to the decisions they made at $t=0,1,2,3$, and 4. Decisions made at $t=5$ represent single-period decisions, because at this stage subjects cannot make subsequent decisions: These decisions are one-shot gambles. To test $\mathrm{H}_{1}$, choosing slot machine $\mathrm{A}$ or $\mathrm{B}$ is regarded as risk-seeking behavior, while choosing slot machine $\mathrm{C}$ or the parent option is seen as risk-averse behavior, splitting the dependent variable into two groups.

The results regarding single-period risk-behavior as presented in Table 1 are consistent with general findings of prospect theory and Sullivan and Kida (1995). That is, the majority of subjects whose wealth is above the aspiration level (Group Above) exhibit risk-averse behavior $\left(\chi^{2}=28.446, p<.000\right)$, while subjects whose wealth is between the starting status and aspiration level (Group Between) show a mixture of risk-seeking and risk-averse behavior $\left(\chi^{2}=4.091, p=.043\right)$, and subjects whose wealth is below their starting status (Group Below) display risk-seeking behavior $\left(\chi^{2}=12.600, p<.000\right)$. Importantly, we find different results for the multi-period decisions as compared to the single-period risk- behavior. For Group Above at $t=$ 1, 2, and 4, no significant differences in risk-behavior are found, while for Group Between the results are widely dispersed across different $t$ 's, and for Group Below there are no significant differences in risk-behavior at $t=2$. Overall, the empirical differences found in individuals' single-period versus multi-period risk-behavior support $\mathrm{H}_{1}$.

Table 1 Single-period and multi-period risk behavior

Total number of subjects choosing a risk-averse (slot machine $\mathrm{C}$ or the parent option) versus a risk-seeking (slot machine A or B) option. Percentages in brackets $D X$ Decision $X$

a Significant difference at the $1 \%$ level ( $\chi^{2}$ test, .5 proportions)

b Significant difference at the $5 \%$ level ( $\chi^{2}$ test, .5 proportions)

\begin{tabular}{llll}
\hline & Group Below & Group Between & Group Above \\
\hline$t=1(\mathrm{D} 2)$ & & & \\
Risk-averse & $23(31.9)$ & $28(36.4)$ & $3(75.0)$ \\
Risk-seeking & $49(68.1)^{\mathrm{a}}$ & $49(63.6)^{\mathrm{b}}$ & $1(25.0)$ \\
$t=2(\mathrm{D} 3)$ & & & \\
Risk-averse & $29(46.0)$ & $22(34.9)$ & $8(57.1)$ \\
Risk-seeking & $34(54.0)$ & $41(65.1)^{\mathrm{b}}$ & $6(42.9)$ \\
$t=3(\mathrm{D} 4)$ & & & \\
Risk-averse & $21(31.8)$ & $22(33.3)$ & $15(75.0)$ \\
Risk-seeking & $45(68.2)^{\mathrm{a}}$ & $44(66.7)^{\mathrm{a}}$ & $5(25.0)^{\mathrm{b}}$ \\
$t=4(\mathrm{D} 5)$ & & & \\
Risk-averse & $19(28.8)$ & $28(44.4)$ & $18(64.3)$ \\
Risk-seeking & $47(71.2)^{\mathrm{a}}$ & $35(55.6)$ & $10(35.7)$ \\
$t=5(\mathrm{D} 6)$ & & & \\
Risk-averse & $11(16.9)$ & $20(36.4)$ & $28(80.0)$ \\
Risk-seeking & $54(83.1)^{\mathrm{a}}$ & $35(63.6)^{\mathrm{b}}$ & $7(20.0)^{\mathrm{a}}$ \\
\hline
\end{tabular}


Table 2 Relative importance of reference points

\begin{tabular}{llllll}
\hline & ANOVA & & Group Below & Group Between & Group Above \\
\hline$t=1$ (D2) & $F=3.098$ & $N$ & 72 & 77 & 4 \\
& $p$ value $=.048$ & Mean & 3.01 & 2.83 & 2.00 \\
& & $p$ value & .396 & & .144 \\
$t=2$ (D3) & $F=3.166$ & $N$ & 63 & 63 & 14 \\
& $p$ value $=.045$ & Mean & 2.80 & 3.02 & 2.45 \\
& & $p$ value & .400 & & .042 \\
$t=3$ (D4) & $F=10.277$ & $N$ & 66 & 66 & 20 \\
& $p$ value $=.000$ & Mean & 3.00 & 2.86 & 2.00 \\
& & $p$ value & .643 & & .000 \\
$t=4$ (D5) & $F=10.285$ & $N$ & 66 & 63 & 28 \\
& $p$ value $=.000$ & Mean & 3.10 & 2.75 & 2.22 \\
& & $p$ value & .063 & & .020 \\
$t=5$ (D6) & $F=31.746$ & $N$ & 65 & 55 & 35 \\
& $p$ value $=.000$ & Mean & 3.32 & 2.93 & 1.86 \\
& & $p$ value & .041 & & .000 \\
\hline
\end{tabular}

Means of subjects' decisions (risk behavior)

\subsection{Reference point shifting}

To test $\mathrm{H}_{2}$, the implications of the value function in Kahneman and Tversky (1979) prospect theory are used to determine the relative importance that subjects attach to their starting status and aspiration level as reference points, respectively. For each $t$, subjects are divided into the same groups as before, namely Group Below, Group Between, and Group Above. Since, we hypothesized that the aspiration level acts as main reference point during the early stages of multi-period decision-making, riskseeking behavior is expected for Group Below and Group Between, while Group Above is expected to show risk-averse behavior. This expectation is based on the fact that the former two groups are positioned in the loss domain of the value function, while the latter group is positioned in the gain domain. Over time, however, our expectation according to $\mathrm{H}_{2}$ is that the starting status becomes a more important reference point. Thus, during later stages of multi-period decision-making, it is expected that Group Below will still exhibit risk-seeking behavior, while Group Between will now display a mixture of risk-seeking and risk-averse behavior, and Group Above will continue to show risk-averse behavior. This is because for the Group Between, the starting status and aspiration work together to create a loss/gain domain mix (see Fig. 2).

We conduct five one-way between-group ANOVAs on risk-behavior to explore the relative importance of both reference points over time. In general, we find that Group Below displays the riskiest behavior and Group Above the least risky behavior, whereas Group Between occupies the middle position in terms of risk-behavior. More interesting, however, are the statistical significant differences found among the three groups (see Table 2). Post-hoc comparisons using the Tukey-HSD test indicate that the mean risk-behavior scores for Group Below do not significantly differ from Group 
Table 3 Relative importance of reference points when the aspiration is unreachable (descriptives)

$R$ Group Reachable, $U$ Group Unreachable

Table 4 Relative importance of reference points when the aspiration is unreachable (analysis)

Means of subjects' decisions (risk behavior)

The subset of subjects used for this analysis is Group Between

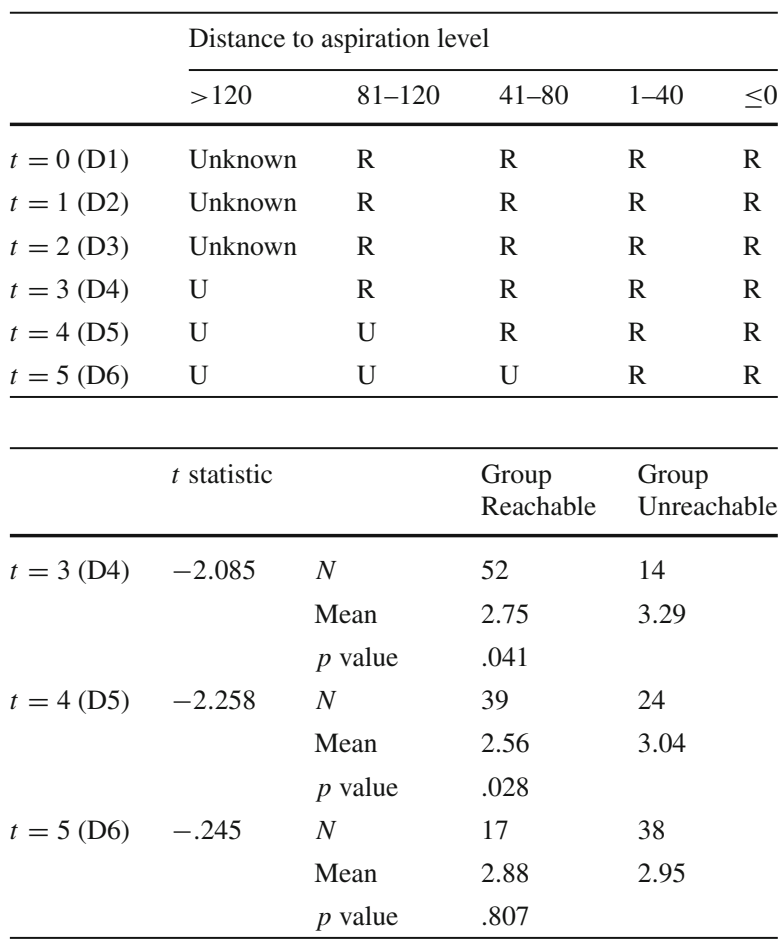

Between at $t=1,2$, and 3, but do significantly differ at $t=4$ and 5, with Group Between showing less risk-seeking behavior. Furthermore, the post-hoc comparisons show significant differences on risk- behavior scores between Group Between and Group Above at all $t$ 's, except $t=1$ (because of the small sample size). These findings support the proposed trend of $\mathrm{H}_{2}$, namely that the aspiration level is the main reference point at the beginning of multi-period decision-making, whereas the starting status becomes more important at the later stages of multi-period decision-making.

To generate a more detailed insight into these results, we examine whether the proposed shifts in reference points are more pronounced for subjects that become unable to reach their aspiration level. It could be expected, that these individuals in particular will set a new, and lower, reference point (i.e., their starting status) to avoid the disutility attached to a situation where (over a longer time period) an aspired goal is just not reached. That is, when positioned in Group Between, we would expect this subset of subjects (labeled Group Unreachable) to display less risky behavior compared to the remaining set of subjects who are still able to reach their aspiration level (labeled Group Reachable). Moreover, we expect Group Unreachable to display a lower utility with the final outcome (measured as the average of a subject's satisfaction, happiness, and regret with the final outcome of the choice experiment).

Independent-samples $t$ tests at $t=3,4$, and 5 examine the differences in riskbehavior and utility between Group Reachable and Group Unreachable when positioned in Group Between (Table 3 explains group compositions). Surprisingly, Group Unreachable exhibits significantly more risky behavior than Group Reachable 
Table 5 Prior outcomes and risk behavior

\begin{tabular}{|c|c|c|c|c|}
\hline & \multicolumn{4}{|c|}{ Scenario } \\
\hline & $L$ & $L L$ & $G$ & $G G$ \\
\hline$N$ & 72 & 29 & 83 & 42 \\
\hline \multicolumn{5}{|l|}{ Mean } \\
\hline Previous decision & 3.04 & 3.31 & 3.04 & 2.81 \\
\hline Current decision & 3.01 & 2.69 & 2.77 & 3.10 \\
\hline$t$ statistic & .228 & 2.768 & 2.688 & -1.909 \\
\hline$p$ value & .820 & .010 & .009 & .063 \\
\hline
\end{tabular}

(Table 4). This finding contradicts the expectation that for these subjects the starting status becomes a more important reference point. Apparently, individuals react strongly in terms of risk-taking to losing the aspiration out of the opportunity set. This reaction could result from disappointment, anger, or lack of care (Shefrin 2002). This explanation is consistent with untabulated utility findings which show that Group Unreachable displays a significantly lower utility than Group Reachable.

\subsection{Prior outcomes and risk-behavior}

To examine the influence of prior outcomes on subjects' risk- behavior $\left(\mathrm{H}_{3}\right)$, we create four scenarios: L, LL, G, and GG. Scenario L means a subject encountered one prior loss, scenario LL represents two consecutive prior losses. Scenario G stands for one prior gain, scenario GG for two consecutive prior gains. For scenarios L and G, subjects were categorized at $t=1$ (i.e., at the second decision moment), and for scenarios LL and GG they were categorized at $t=2$ (i.e., at the third decision moment). For each scenario, we check whether subjects take more or less risk compared to their prior decision. To do so, a repeated-measures ANOVA was conducted for each scenario with risk- behavior as within-subjects factor (see Table 5).

Regarding the loss scenarios, we observe no significant difference in risk-behavior in scenario $\mathrm{L}(M=3.04$ vs. 3.01, $p$ value $=.820)$, but we do observe a significant shift in risk-behavior in scenario LL, where more risk-averse behavior is shown compared to the previous decision $(M=3.31$ vs. $2.69, p$ value $=.010)$. These findings support $\mathrm{H}_{3 \mathrm{~d}}$ but not $\mathrm{H}_{3 \mathrm{a}}$. Apparently, losing once does not entice subjects to become less riskseeking, but losing twice does (cf. Odean et al. 2005). In line with our predictions, the further an individual (over time) moves away from his or her aspiration level, the stronger the shift towards risk-averse behavior becomes.

For the two gain scenarios ( $G$ and $G G)$, we find significant differences in riskbehavior. In scenario $\mathrm{G}$, less risk-seeking behavior is observed compared to the previous decision $(M=3.04$ vs. $2.77, p$ value $=.009)$. This finding contradicts Sullivan and Kida (1995), who found that more risk-taking behavior is observed in the presence of prior gains as compared to prior losses, but supports Denrell (2004), who claims risk-taking is a decreasing function of the performance-aspiration gap. Contrary to scenario $\mathrm{G}$, the results of scenario GG suggest that individuals become more risk-seeking after having experienced gains twice, as predicted ( $M=2.81$ vs. 3.10, 
$p$ value $=.063$ ). All in all, the results support $\mathrm{H}_{3 b}$ and $\mathrm{H}_{3 \mathrm{c}}$ and show that individuals become more cautious after experiencing one gain to secure it, but feel that they can allow themselves to take more risk when prior gains become large enough.

\section{Conclusion}

This study contributes to the scant experimental evidence on the evolution of riskbehavior in a multi-period decision context. In particular, we respond to Shefrin and Statman (2000) call for the development of a multi-period model to examine the link between risk-behavior and aspirations. This paper is amongst the first to integrate into one study the ideas of shifting and multiple reference points, multi-period decisionmaking under risk, and aspiration levels.

The results of this paper are promising in several ways. First, they demonstrate that a multi-period feature is important to better understand and predict individuals' risk-behavior. Second, the results indicate that aspiration levels act as main reference point during the early stages of decision-making, whereas the starting status becomes an important reference point during later stages. Third, the results show how prior outcomes influence subsequent choices.

The set-up of our experiment has some limitations that provide avenues for future research. First, subjects could not learn about the gambling game beforehand. Therefore, one may be concerned whether the results reflect deliberate choice or confusion (Weber and Zuchel 2005). We minimized this concern by encouraging subjects to ask for clarification. Second, the aspiration level is self-reported. Theory and empirical research suggest that self-report measures represent a mixture of sociological, psychological, contextual, and experiential effects (Harrison et al. 1996; Lanyon and Goodstein 1997). Still, for constructs like values and attitudes, self-report is considered superior, as the subject's commitment to a self-set aspiration level increases the reliability of their risk-taking behavior (Howard 1994). Third, offering subjects the parent option could alter their risk preferences. This is because of the status-quo bias, which provides an opportunity to remain (roughly) at the current (wealth) position (Samuelson and Zeckhauser 1988). Fourth, the current study did not assess the impact of personality characteristics and situational factors such as stress that might cause differences in individuals' risk-behavior over time (see e.g., Porcelli and Delgado 2009).

Acknowledgements The authors thank the editor, Mohammed Abdellaoui, for his constructive guidance through the review process. For their comments on previous drafts of this paper and their help in administering the experiment, the authors thank Anne Klesse, Martin Strobel, and seminar participants at Maastricht University's Behavioral and Experimental Economics Laboratory meetings. We thank Donna Maurer for her editorial assistance. This paper is based on the work done by the second author as part of fulfilling the requirements for obtaining a M.Sc. degree.

Open Access This article is distributed under the terms of the Creative Commons Attribution License which permits any use, distribution, and reproduction in any medium, provided the original author(s) and the source are credited. 


\section{References}

Ackert, L. F., Charupat, N., Church, B. K., \& Deaves, R. (2006). An experimental examination of the house money effect in a multi-period setting. Experimental Economics, 9(1), 5-16.

Arkes, H. R., Hirshleifer, D., Jiang, D., \& Lim, S. (2008). Reference point adaptation: Tests in the domain of security trading. Organizational Behavior and Human Decision Processes, 105(1), 67-81.

Benartzi, S., \& Thaler, R. (1995). Myopic loss aversion and the equity premium puzzle. Quarterly Journal of Economics, 110(1), 73-92.

Bleichrodt, H. (2007). Reference-dependent utility with shifting reference points and incomplete preferences. Journal of Mathematical Psychology, 51(4), 266-276.

Cohen, M., Etner, J., \& Jeleva, M. (2008). Dynamic decision making when risk perception depends on past experience. Theory and Decision, 64(2-3), 173-192.

Dellavigna, S., \& LiCalzi, M. (2001). Learning to make risk neutral choices in a symmetric world. Mathematical Social Sciences, 41(1), 19-37.

Denrell, J. (2004). Risk taking and aspiration levels: Two alternative null-models. Academy of Management Proceedings, pp.J1-J6.

Diecidue, E., \& Van De Ven, J. (2008). Aspiration level, probability of success and failure, and expected utility. International Economic Review, 49(2), 683-700.

Endres, M. L. (2006). The effectiveness of assigned goals in complex financial decision making and the importance of gender. Theory and Decision, 61(2), 129-157.

Fischbacher, U. (2007). z-Tree: Zurich toolbox for ready-made economic experiments. Experimental Economics, 10(2), 171-178.

Gneezy, U., \& Potters, J. (1997). An experiment on risk taking and evaluation periods. The Quarterly Journal of Economics, 112(2), 631-645.

Gooding, R. Z., Goel, S., \& Wiseman, R. M. (1996). Fixed versus variable reference points in the risk-return relationship. Journal of Economic Behavior and Organization, 29(2), 331-350.

Harrison, D. A., McLaughlin, M. E., \& Coalter, T. M. (1996). Context, cognition and common method variance: Psychometric and verbal protocol evidence. Organizational Behavior and Human Decision Processes, 68(3), 246-261.

Heath, C., Larrick, R. P., \& Wu, G. (1999). Goals as reference points. Cognitive Psychology, 38(1), 79-109.

Heyman, J. E., Mellers, B., Tishcenko, S., \& Schwartz, A. (2005). Shifting reference points and fleeting pleasures. Advances in Consumer Research, 32, 116-117.

Howard, G. S. (1994).Why do people say nasty things about self-reports? Journal of Organizational Behavior, 15(5), 399-404.

Itami, H. (1976). Analysis of implied risk-taking behavior under a goal-based incentive scheme. Management Science, 23(2), 183-197.

Kahneman, D., \& Tversky, A. (1979). Prospect theory: An analysis of decision under risk. Econometrica, 47(2), 263-292.

Lanyon, R. I., \& Goodstein, L. D. (1997). Personality Assessment (3rd ed.). New York: Wiley.

Lim, R. G. (1995). A range-frequency explanation of shifting reference points in risky decision making. Organizational Behavior and Human Decision Processes, 63(1), 6-20.

Liu, H.-H., \& Colman, A. M. (2009). Ambiguity Aversion in the long run: Repeated decisions under risk and uncertainty. Journal of Economic Psychology, 30(3), 277-284.

Loewenstein, G. (1987). Anticipation and valuation of delayed consumption. Economic Journal, 97(387), $667-684$.

Loewenstein, G. (1988). Frames of mind in intertemporal choice. Management Science, 34(2), $210-214$.

Loewenstein, G., \& Prelec, D. (1991). Negative time preference. American Economic Review, 81(2), 347352.

Lopes, L. L. (1987). hope and fear: The psychology of risk. Advances in Experimental Social Psychology, 20, 255-295.

Munro, A., \& Sugden, R. (2003). On the theory of reference-dependent preferences. Journal of Economic Behavior and Organization, 50(4), 407-428.

Odean, T., Strahilevitz, M., \& Barber, M. B. (2005). Once burned twice shy, this stock has been good to me so far, and it could have been worse: How naïve learning and counterfactuals influence the repurchase of stocks previously sold. Advances in Consumer Research, 32, 204.

Page, L., Garboua, L. L., \& Montmarquette, C. (2007). Aspiration levels and educational choices: An experimental study. Economics of Education Review, 26(6), 748-758. 
Payne, J., Laughhunn, D., \& Crum, R. (1980). Translation of Gambles and Aspiration Level Effects in Risky Choice Behavior. Management Science, 26(10), 1039-1060.

Porcelli, A. J., \& Delgado, M. R. (2009). Acute stress modulates risk taking in financial decision making. Psychological Science, 20(3), 278-283.

Rachlin, H. (1990).Why do people gamble and keep gambling despite heavy losses? Psychological Science, 1(5), 294-297.

Samuelson, W. P., \& Zeckhauser, R. (1988). Status quo bias in decision making. Journal of Risk and Uncertainty, 1(1), 7-59.

Schmidt, U. (2003). Reference dependence in cumulative prospect theory. Journal of Mathematical Psychology, 47(2), 122-131.

Shefrin, H. (2002). Beyond greed and fear: Understanding behavioral finance and the psychology of investing. Oxford.: Oxford University Press.

Shefrin, H., \& Statman, M. (2000). Behavioral portfolio theory. Journal of Financial and Quantitative Analysis, 35(2), 127-151.

Sugden, R. (2003). Reference-dependent subjective expected utility. Journal of Economic Theory, $11(2), 172-191$.

Sullivan, K., \& Kida, T. (1995). The effect of multiple reference points and prior gains and losses on managers' risky decision making. Organizational Behavior and Human Decision Processes, 64(1), 76-83.

Thaler, R. H., \& Johnson, E. J. (1990). Gambling with the house money and trying to break even. Management Science, 36(6), 643-660.

Tversky, A., \& Kahneman, D. (1981). The framing of decisions and the psychology of choice. Science, 211(4481), 453-458.

Weber, E. U., \& Milliman, R. A. (1997). Perceived risk attitudes: Relating risk perception to risky choice. Management Science, 43(2), 123-144.

Weber, M., \& Zuchel, H. (2005). How do prior outcomes affect risk attitude? Comparing escalation of commitment and the house-money effect. Decision Analysis, 2(1), 30-43.

Zeisberger, S., Langer, T., \& Weber, M. (2012). Why does myopia decrease the willingness to invest? Is it myopic loss aversion or myopic loss probability aversion? Theory and Decision, 72(1), 35-50. 